\title{
ARQUEOLOGIA BIOMOLECULAR: PASSOS PRELIMINARES PARA INTERPRETAÇÕES SOBRE A ORIGEM DOS RESÍDUOS ORGÂNICOS PRESERVADOS EM FRAGMENTOS DE CERÂMICA PRÉ-COLONIAL NO BRASIL
}

\author{
Fabrício Augusto Hansel, Sandro Lucio Mireski e Luiz Augusto dos Santos Madureira* \\ Departamento de Química, Universidade Federal de Santa Catarina, CP 476, 88040-900 Florianópolis - SC, Brasil \\ Teresa Domitila Fossari \\ Museu Universitário Prof. Oswaldo Rodrigues Cabral, Universidade Federal de Santa Catarina, CP 476, \\ 88040-900 Florianópolis - SC, Brasil
}

Recebido em 24/11/04; aceito em 14/10/05; publicado na web em 14/3/06

\begin{abstract}
BIOMOLECULAR ARCHAEOLOGY: PRELIMINARY STEPS FOR INTERPRETATION OF THE ORIGIN OF PRESERVED ORGANIC RESIDUES IN BRAZILIAN PRE-COLONIAL POTSHERDS. Organic residue analysis of archaeological potsherds is a well-established method for determining the uses of European and North American pottery vessels. In the present work we assess if the organic residues identified in Brazilian potsherd extracts are related to commodity processes (e.g. cooking or surface treatment) or to other non-archaeological sources, using as a model potsherds recovered from the Rio do Meio site (Santa Catarina Island). The potsherd extracts are dominated by saturated fatty acids $\left(\mathrm{Ac}_{16: 0}\right.$, with lower abundances of $\mathrm{Ac}_{14: 0}$ and $\left.\mathrm{Ac}_{18: 0}\right)$. Our studies provide evidence that the organic residues preserved in the Brazilian archeological potsherds are related to foodstuffs and surface treatment processes of the pottery vessels.
\end{abstract}

Keywords: potsherds; archaeology; lipids.

\section{INTRODUÇÃO}

Arqueologia biomolecular é o estudo de biomoléculas antigas relacionadas a alguma atividade dos homens no passado ${ }^{1}$. Entre as classes de compostos orgânicos recuperados de materiais arqueológicos, os lipídios (componentes biológicos solúveis em solventes orgânicos) estão em destaque, sendo comumente encontrados em artefatos e ecofatos (i.e. material lítico, fragmentos de cerâmica, ossos e concreções). A presença destes em contextos arqueológicos devese à resistência à degradação, atribuída principalmente às cadeias saturadas de carbonos que lhes conferem um caráter hidrofóbico ${ }^{1}$. Inicialmente, os estudos sobre matéria orgânica amorfa em materiais arqueológicos eram limitados pelas técnicas analíticas ${ }^{2}$. Hoje em dia, com os contínuos avanços da química analítica e da bioquímica, a recuperação e caracterização dos resíduos orgânicos arqueológi$\cos$ (principalmente os lipídios), mesmo que alterados por mecanismos de degradação como hidrólise e oxidação, fornecem excelentes bases para determinar suas origens biológicas.

Nos últimos 30 anos, através das técnicas de cromatografia gasosa (GC) e cromatografia gasosa acoplada à espectrometria de massas (GC-MS), a caracterização dos lipídios preservados em fragmentos de cerâmica possibilitou identificar o processamento de vários tipos de produtos com origem animal e vegetal (gorduras animais, óleos vegetais, resinas e ceras) $)^{3,4}$. A presença de triterpenos, ésteres de cadeias longas $\left(\mathrm{Es}_{20: 0}-\mathrm{Es}_{60: 0}\right)$ e fitoesteróis são indicativos de contribuição vegetal. Por outro lado, a identificação de ácidos graxos pode tanto indicar o uso de óleos vegetais como de gorduras animais. Nestes casos, o uso da distribuição dos ácidos graxos saturados, uma vez que os ácidos insaturados raramente estão preservados como componentes significantes nos resíduos orgânicos extraídos dos fragmentos de cerâmica, e a presença de alguns biomarcadores, ajudam na distinção preliminar entre óleo vegetal e gordura animal. Por ex., a distribuição relativa dos ácidos graxos

*e-mail: madureira@qmc.ufsc.br saturados ímpares (e.g. $\mathrm{Ac}_{15: 0} \mathrm{e} \mathrm{Ac}_{\text {17:0 }}$ ), geralmente encontrados em menor abundância em óleos de origem vegetal, a construção de diagramas baseados nas razões criadas a partir da distribuição dos ácidos graxos identificados nos vasilhames (e.g. $\mathrm{Ac}_{12: 0} / \mathrm{Ac}_{14: 0}$ versus $\mathrm{Ac}_{\text {16:0 }}\left(\mathrm{Ac}_{18: 0}\right)$ e a identificação dos ácidos graxos iso e anteiso, comuns em gorduras animais e geralmente ausentes em óleos vegetais, distinguem estas duas fontes ${ }^{5,6}$. Entretanto, a utilização desses métodos deve ser extremamente cautelosa, pois são distribuições comparadas com amostras de referência contemporâneas, o que nem sempre é possível devido a mudanças pré-deposicionais (e.g. hidrólise e oxidação durante o cozimento) e pós-deposicionais (e.g. diagênese) ${ }^{7}$. Do mesmo modo, a presença dos ácidos iso e anteiso pode ser uma contribuição bacteriana ${ }^{8}$.

Os lipídios adsorvidos nos fragmentos de cerâmica recuperados de sítios arqueológicos podem ser provenientes basicamente das seguintes fontes: pasta de argila, aditivos orgânicos (antiplásticos) adicionados na confecção da peça, aquecimento (e.g. impregnação da fuligem), migração dos sedimentos, uso (e.g. cozinhar) ou tratamento da superfície do vasilhame, além de contaminações devido ao contato inapropriado das mãos e condições de armazenamento $0^{9,10}$ inadequadas.

Entre as possíveis fontes de lipídios registradas acima, Johnson et al. ${ }^{11}$ demonstraram, usando as técnicas espectroscopia na região do infravermelho (IR) e análise elementar (CHN), que se a queima do vasilhame durante a fabricação exceder os $600{ }^{\circ} \mathrm{C}$, nenhuma ligação de hidrogênio orgânico é preservada. Elimina-se assim a origem da matéria orgânica presente nos fragmentos de cerâmica arqueológica como sendo oriunda da pasta da argila e/ou dos antipláticos (e.g. conchas, ossos e restos vegetais). Com respeito à migração dos lipídios presentes no sedimento do ambiente de deposição, Heron et $a l .^{10}$ concluíram que esta não afetaria a composição dos resíduos orgânicos adsorvidos nos vasilhames. Contaminações como contato inapropriado das mãos e péssimas condições de armazenamento podem ser excluídas com um tratamento abrasivo, através do qual somente os lipídios que migraram para o interior da parede do 
vasilhame são estudados. Com isso, a presença de lipídios no extrato orgânico dos fragmentos de cerâmica está associada ao uso e/ou tratamento da superfície do vasilhame, sendo uma importante fonte de informação arqueológica. Esses dados apresentados condizem com vasilhames produzidos por populações arqueológicas européias e norte-americanas ${ }^{9-11}$. No que tange à arqueologia brasileira poderse-ia perguntar se, uma vez que as condições dos ambientes de deposição e as técnicas de confecção e queima dos vasilhames não são necessariamente as mesmas, os preceitos confirmados se aplicariam à produção de vasilhames pelas populações pré-coloniais que ocuparam o atual território brasileiro.

Com respeito à literatura etnográfica brasileira, especificamente a que se refere à produção de vasilhames por populações indígenas, comenta-se que os vasilhames de cerâmica eram queimados durante a confecção em fogos abertos, em sua maioria com atmosfera oxidante, a uma temperatura de aproximadamente $600{ }^{\circ} \mathrm{C}^{12,13}$. Estudos envolvendo fragmentos de cerâmica arqueológica da Ilha de Santa Catarina (sítio Rio do Meio) demonstraram através da técnica de difração de raio X (XRD), baseados na presença ou não de Caolinita e Metacaolinita, que a temperatura alcançada durante a queima do vasilhame foi superior a 400 e inferior a $600{ }^{\circ} \mathrm{C}^{14}$. Com a utilização dessa mesma técnica, um outro trabalho com fragmentos de cerâmica de grupos pré-coloniais, que habitavam regiões correspondentes aos atuais estados de São Paulo, Minas Gerais e Espírito Santo, também demonstrou que a temperatura de queima, para a maioria das peças, era superior a $500{ }^{\circ} \mathrm{C}$ e possivelmente acontecia em "fogueiras abertas" 15.

O presente estudo tem dois objetivos principais: constatar a presença e identificar preliminarmente quais as classes químicas de resíduos orgânicos que estão presentes nos fragmentos de cerâmica arqueológica aqui no Brasil e se esses resíduos apresentam como principais fontes o uso e/ou tratamento da superfície dos mesmos. Essas informações são de grande importância para os estudos em arqueologia, pois fornecem dados a respeito dos processos utilizados nos vasilhames de cerâmica pelas populações précoloniais. Para responder essas questões, focalizou-se o estudo em fragmentos recuperados do sítio arqueológico do Rio do Meio, na Ilha de Santa Catarina, associado à população pré-colonial Jề ${ }^{16,17}$.

\section{PARTE EXPERIMENTAL}

\section{O sítio arqueológico do Rio do Meio e os vasos de cerâmica da população pré-colonial Jê}

$\mathrm{Na}$ área do sítio Rio do Meio foram encontradas evidências de dois locais de habitação, Área I $\left(98 \mathrm{~m}^{2}\right)$ e Área II $\left(350 \mathrm{~m}^{2}\right)$, separadas por um intervalo de $58 \mathrm{~m}$. Esses locais estavam assentados sobre sedimentos arenosos holocênicos, junto à praia de Jurerê e à baía ampla, quase no norte da Ilha de Santa Catarina (Figura 1). Em nenhuma das duas áreas foi encontrado sepultamento humano.

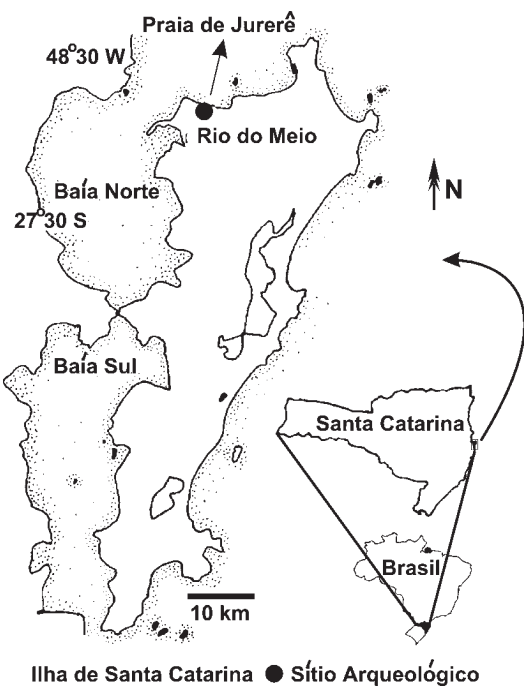

Figura 1. Localização do sítio arqueológico do Rio do Meio

A área II foi datada do ano de $1170 \mathrm{AD}\left({ }^{14} \mathrm{C}\right){ }^{17}$. No sítio Rio do Meio foram encontrados vestígios de fogueiras, artefatos líticos (machados, batedores e polidores) e cerâmicos (550 fragmentos simples), ecofatos orgânicos (ossos de mamíferos terrestres e aquáticos e de peixes, além de conchas) e ecofatos inorgânicos (seixos rolados, além de fragmentos líticos) ${ }^{17}$.

Os vasilhames de cerâmica produzidos pelos grupos pré-coloniais Jê da costa catarinense, em geral, possuíam diâmetro de boca em torno de 20 a $40 \mathrm{~cm}$ e não eram decorados. Os fragmentos recuperados apresentaram uma coloração preta alaranjada, cor essa característica dos fragmentos de cerâmica recuperados dos sítios pré-coloniais Jêt ${ }^{16-20}$. Vale ressaltar que este trabalho não procura associar a forma do vasilhame com a presença e/ou distribuição dos lipídios, pois não foi estabelecida a posição dos fragmentos no vasilhame de origem (Tabela 1). A Figura 2 apresenta, de maneira didática, as formas mais comuns dos vasilhames de cerâmica produzidos pela população pré-colonial Jê. Essas formas foram deduzidas por Piazza e Eble ${ }^{20}$ a partir de fragmentos de bordas de cerâmica (desenhados em preto na Figura 2) recuperados em escavações arqueológicas.

\section{Origem dos resíduos orgânicos adsorvidos nos vasilhames arqueológicos}

As amostras analisadas foram selecionadas do material proveniente de escavações arqueológicas do sítio do Rio do Meio II, o qual foi dividido em diferentes quadras de $1 \mathrm{~m}^{2}$ de área (contexto horizontal), cujos cortes verticais atingiram camadas variando entre 5 e $10 \mathrm{~cm}$ de espessura - denominados níveis (contexto verti-

Tabela 1. Contextos arqueológicos nos quais foram selecionados os fragmentos de cerâmica e sedimentos para análise dos lipídios

Contextos Descrição dos contextos Descrição do fragmento de cerâmica

Quadra/Nível

F18/5 Etnoestrato: restos faunísticos (ossos) e núcleos de carvão. Litoestratos: areia clara com manchas escuras, núcleos de carvão

$\mathrm{K} 22 / 2$ Etnoestrato: restos faunísticos (conchas). Litoestratos: areia clara. Elementos pós- deposicionais: raízes

Q21/3 Etnoestrato: restos faunísticos (conchas). Litoestratos: areia escura. Elementos pós-deposicionais: raízes. Próximo ao mar
Cor preta alaranjada, não apresentava nenhum resíduo carbonizado na superfície do vasilhame. Posição do fragmento no vasilhame não foi determinada Idem ao fragmento F18/5

Idem ao fragmento F18/5 
A

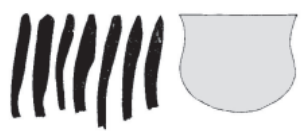

B

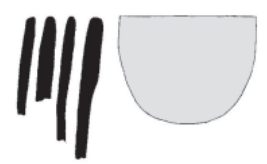

C

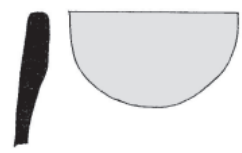

D
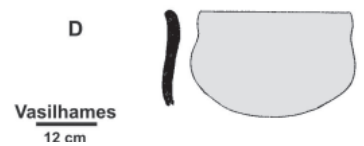

Figura 2. Forma dos vasos produzidos pela população pré-colonial Jê que ocupava a costa de Santa Catarina. Estes vasos foram reconstruídos comparando-se a forma do topo dos fragmentos de cerâmica (em preto) coletados no sítio arqueológico situado na cidade de Joinville. As letras demonstram quatro tipos diferentes de bordas (A) extrovertidas, $(B)$ diretas, (C) reforçadas externamente e $(D)$ introvertidas. As figuras cinzas são as possíveis formas deduzidas por Piazza e Eble Eb $^{20}$

cal), um universo de aproximadamente 300 quadras (Tabela 1). As quadras, das quais as amostras foram selecionadas, formavam entre si um triângulo escaleno de arestas (distância entre os pontos de coleta) que mediam aproximadamente 3,5 e $9 \mathrm{~m}$.

Primeiramente, com o intuito de eliminar as contaminações pós-escavações citadas, o trabalho foi desenvolvido com os resíduos adsorvidos no interior da parede do vasilhame arqueológico.

Para avaliar a presença dos lipídios procedentes da pasta original realizou-se simulação envolvendo a temperatura de $500{ }^{\circ} \mathrm{C}$, que é a média da temperatura determinada para queima dos vasilhames ${ }^{14}$, com um sedimento argiloso de conhecida composição lipídica e teor de carbono orgânico ${ }^{21}$.

Com relação à possível migração dos lipídios presentes no sedimento, comparou-se a distribuição lipídica dos extratos orgânicos obtidos dos fragmentos com a composição lipídica presente nos extratos orgânicos dos sedimentos arqueológicos de mesmo contexto.

A origem dos lipídios devido à impregnação de fumaça foi avaliada pela presença ou não de biomarcadores produzidos durante a queima de biomassa ${ }^{22}$.

\section{Vidraria e solventes}

Todos os solventes usados foram grau HPLC ou superior (Rathburn e Tedia). Quando do uso de água destilada, esta foi extraída duas vezes com $\mathrm{CH}_{2} \mathrm{Cl}_{2}$. A vidraria reutilizável foi limpa deixando-a imersa em uma solução de detergente por $24 \mathrm{~h}$, depois enxaguada com água em abundância e acetona, nesta sequiência, e então calcinada a $450{ }^{\circ} \mathrm{C}$ por, no mínimo, $4 \mathrm{~h}$. Antes de usar qualquer vidro, estes eram enxaguados com a mistura de solventes $\mathrm{CHCl}_{3}: \mathrm{CH}_{3} \mathrm{OH}(2: 1)$.

\section{Simulação de queima}

A resistência dos lipídios frente ao calor foi realizada em laboratório à temperatura de $500{ }^{\circ} \mathrm{C}$, utilizando um forno tubular (Quimlab - Joinville). Os testes de queima, em triplicata, foram realizados em atmosfera oxidante e redutora (sob fluxo constante de nitrogênio, $1 \mathrm{~L} \mathrm{~min}^{-1}$ ) com $\approx 2,0 \mathrm{~g}$ de sedimento rico em argila $(\approx 44 \%)$ e de conhecida composição lipídica e teor de carbono orgânico $^{20}$. O tempo de queima durante os testes foi de $1 \mathrm{~h}$ e 30 min, que é o tempo médio usado pela população indígena brasileira para fabricação de seus vasilhames ${ }^{12,13}$.

\section{Tratamento antes da extração}

\section{Fragmentos de cerâmica}

As superfícies das amostras foram limpas com um polidor portátil elétrico ("eletric hand-drill”) e, em seguida, maceradas em um gral com um pistilo. A amostra pulverizada foi então submetida à extração.

\section{Sedimento}

As amostras de sedimentos foram primeiramente secas em estufa por $24 \mathrm{~h}$ à $60{ }^{\circ} \mathrm{C}$. Após secagem os sedimentos foram peneirados utilizando-se uma peneira de malha $0,5 \mathrm{~mm}$. Esse procedimento foi realizado para remover raízes, galhos e conchas presentes no sedimento, sendo a fração $<0,5 \mathrm{~mm}$ utilizada na extração.

\section{Extrações com solventes}

Foram utilizados $\approx 2,0 \mathrm{~g}$ de fragmento de cerâmica e $\approx 5,0 \mathrm{~g}$ de sedimento. Os lipídios foram extraídos usando-se uma mistura de solventes $\mathrm{CHCl}_{3}: \mathrm{CH}_{3} \mathrm{OH}(2: 1 \mathrm{v} / \mathrm{v}, 10 \mathrm{~mL}, 2$ x $15 \mathrm{~min}$ no ultrassom). Os extratos contendo os lipídios foram então centrifugados (25 min, $2500 \mathrm{rpm}$ ), decantados e filtrados através de uma micro coluna preenchida com sílica gel (eluente $\mathrm{CHCl}_{3}: \mathrm{CH}_{3} \mathrm{OH}, 2: 1 \mathrm{v} / \mathrm{v}$ ). As quantificações foram realizadas com o método de padronização interna, utilizando-se $30 \mu \mathrm{g}$ do padrão $5 \alpha$-colestano e/ou $50 \mu \mathrm{g}$ de hexadecano deuterado $\left(\mathrm{C}_{16} \mathrm{D}_{34}\right)$.

\section{Derivatizações}

\section{Esterificação/transesterificação}

$\mathrm{O}$ extrato orgânico, dissolvido em $1 \mathrm{~mL}$ de tolueno, foi esterificado com 2,0 mL de uma solução de $\mathrm{CH}_{3} \mathrm{OH}$ :cloreto de acetila (9:1). A solução foi mantida em estufa por $12 \mathrm{~h}$ à temperatura entre 50-60 ${ }^{\circ} \mathrm{C}$, sob atmosfera de $\mathrm{N}_{2}$. Após adicionou-se $1 \mathrm{~mL}$ de solução aquosa de $\mathrm{KCl}(10 \% \mathrm{~m} / \mathrm{v})$. O extrato orgânico foi extraído com $\mathrm{CHCl}_{3}(3 \times 1 \mathrm{~mL})$ e ,em seguida, submetido a uma micro coluna de vidro contendo sulfato de sódio anidro. Por fim, o extrato orgânico foi seco sob fluxo de $\mathrm{N}_{2}$ e armazenado em refrigerador.

\section{Silanização (BSTFA)}

Após a esterificação, os derivados trimetilsilil (TMS) éter foram obtidos adicionando-se aos extratos secos $40 \mu \mathrm{L}$ de uma solução contendo N,O-bis(trimetilsilil)trifluoracetamida (BSTFA, Sigma) contendo $1,0 \%$ de trimetilclorossilano, que foi aquecida por $1 \mathrm{~h}$ à $70^{\circ} \mathrm{C}$. $\mathrm{O}$ excesso de BSTFA foi evaporado sob um fluxo de $\mathrm{N}_{2}$ e as amostras, dissolvidas em $80 \mu \mathrm{L}$ de hexano, foram analisadas por GC e GC-MS em até $24 \mathrm{~h}$.

\section{Cromatografia gasosa e cromatografia gasosa acoplada à espectrometria de massas}

Coluna cromatográfica usada: CBP1 $\left(25 \mathrm{~m}\right.$ x $0,32 \mathrm{~mm} ; \mathrm{d}_{\mathrm{f}} 0,25$ $\mu \mathrm{m})$; programação do forno: temperatura inicial $40^{\circ} \mathrm{C}$, taxa de aquecimento $10{ }^{\circ} \mathrm{C} \min ^{-1}$ até $150{ }^{\circ} \mathrm{C}$, então $4{ }^{\circ} \mathrm{C} \min ^{-1}$ até $310^{\circ} \mathrm{C}$ e isoterma de $10 \mathrm{~min}$. Volume injetado: $1 \mu \mathrm{L}$, utilizando o modo sem divisão de fluxo ("splitless") por $30 \mathrm{~s}$.

As análises por GC foram realizadas no aparelho da marca Shimadzu (GC-17A), dotado de injetor com e sem divisão de fluxo ("split/splitless") e gás de arraste $\mathrm{N}_{2}$. 
As análises por GC-MS foram realizadas em um equipamento da marca Shimadzu (GC-MS-QP2000 A) acoplado a um cromatógrafo a gás da marca Shimadzu (GC-14B), dotado de injetor com e sem divisão de fluxo. $\mathrm{O}$ espectrômetro de massas foi programado para trabalhar com a variação de massa/carga $(\mathrm{m} / \mathrm{z})$ entre $50-600 \mathrm{com}$ tempo total de ciclo de 1,0 s. Condições extras do MS: a temperatura da fonte de íons foi mantida a $170{ }^{\circ} \mathrm{C}$, a emissão de corrente a 300 $\mu \mathrm{A}$ e o potencial de elétron ionização a $70 \mathrm{eV}$. A interface GC-MS foi mantida a $300{ }^{\circ} \mathrm{C}$ e hélio foi usado como gás de arraste. Os picos foram identificados com ajuda da biblioteca eletrônica de espectro de massas NIST/EPA/NHI versão 4.5, 1994.

\section{RESULTADOS E DISCUSSÃO}

Os extratos totais de lipídios dos fragmentos de cerâmica produziram ácidos graxos livres como compostos mais abundantes (Tabela 2). A Figura 3 apresenta o cromatograma parcial do extrato total do fragmento de cerâmica recuperado do contexto F18/5. Os extratos são dominados pela distribuição dos ácidos graxos com cadeias hidrocarbônicas inferiores a 24 átomos de carbono. O ácido palmítico $\left(\mathrm{Ac}_{1600}\right)$ aparece em maior quantidade, seguido dos ácidos esteárico $\left(\mathrm{Ac}_{\text {18:0 }}\right)$ e mirístico $\left(\mathrm{Ac}_{14: 0}\right)$, sendo essa distribuição característica de óleos degradados (os ácidos graxos insaturados são predominantes em óleos) $)^{24}$. A presença significativa dos ácidos graxos com números ímpares de átomos de carbono (ácido pentadecanóico e heptadecanóico), dos éteres de glicerol, do colesterol e, principalmente, do ácido fitânico indicam, preliminarmente, como fontes desses resíduos, as gorduras de origem animal, uma vez que estes estão ausentes, ou encontram-se em baixas concentrações em óleos vegetais ${ }^{24}$. Os demais compostos detectados são produtos da degradação oxidativa dos ácidos graxos monoinsaturados e do colesterol, respectivamente os hidroxiácidos e um ceto-esterol $^{25-28}$. Como já se poderia prever, a quantidade detectada de ácidos graxos insaturados não é equiparável à encontrada em gorduras de animais contemporâneos devido à degradação ${ }^{24}$.

Fontes alternativas dos lipídios, que não sejam o uso e/ou tratamento da superfície dos vasilhames, como migração do sedimento arqueológico, da pasta da argila e do antiplástico, foram testadas

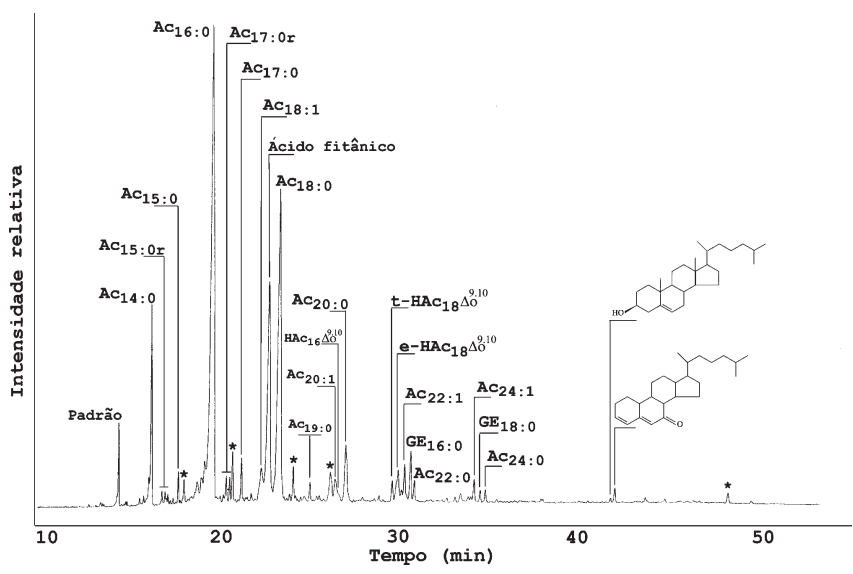

Figura 3. Cromatograma parcial do extrato total do fragmento de cerâmica recuperado no contexto F18/5. No qual: A $\boldsymbol{c}_{x: y}$ são os ácidos graxos, $\boldsymbol{x}$ é o numero de átomos de carbono, $\boldsymbol{y}$ é o número de insaturações; $\boldsymbol{G E}$ são os éteres de glicerol; HAc são os hidroxiácidos; $\boldsymbol{t}$ e e são treo e erito, respectivamente, e $\Delta \boldsymbol{o}^{n, m}$, onde $n$ e $m$ são as posições das hidroxilas com relação à posição $\Delta$. Padrão interno: hexadecano deuterado $\left(C_{16} D_{34}\right)$. * Denota contaminantes e ramificado em laboratório a fim de assegurar a interpretação de que os lipídios podem ser usados como fonte de informações a respeito das populações passadas.

Heron et al. ${ }^{10}$ demonstraram ser pouco provável a migração dos lipídios presentes no sedimento. Entretanto, para avaliar essa hipótese, os extratos orgânicos de três fragmentos de cerâmica foram comparados com os extratos orgânicos do sedimento de mesmo contexto arqueológico (Figura 4). Percebe-se a nítida diferença entre os perfis cromatográficos expostos; não há nenhuma relação entre a composição lipídica do sedimento com a apresentada pelo fragmento, indicando assim a não interferência dos lipídios presentes no sedimento. Qualitativamente, a distribuição lipídica nos fragmentos de cerâmica é composta essencialmente por ácidos graxos com cadeias inferiores a 24 átomos de carbono. Quanto ao sedimento a distribuição é mais variável, apresentando de forma distinta ácidos graxos e álcoois com cadeias hidrocarbônicas superiores a 20 átomos, com os de números pares mais abundantes que os de ímpares (Tabela 2). A origem destes compostos reflete, provavelmente, a flora que cobria o antigo assentamento durante a ocupação ou que se desenvolveu após o seu abandono. Como principais fontes para esses compostos no sedimento citam-se as ceras epicuticulares, a cutina e/ou a suberina, presentes na composição estrutural dos vegetais ${ }^{29,30}$.

A distribuição quantitativa dos lipídios presentes nos sedimentos e nos fragmentos de cerâmica também é distinta (Tabela 2). A variação quantitativa dos lipídios nos sedimentos $\left(85-667 \mu \mathrm{g} \mathrm{g}^{-1}\right)$ é menor que nos fragmentos de cerâmica $\left(\approx 1-3964 \mu \mathrm{g} \mathrm{g}^{-1}\right)$. Esse resultado pode ser interpretado como sendo devido à maior variabilidade de uso a que estão sujeito os vasilhames de cerâmica. Por ex., os vasilhames utilizados para cozinhar apresentam concentrações de lipídios maiores que aqueles usados para estocagem ${ }^{31}$.

A presença de lipídios provenientes da combustão não foi detectada nos fragmentos analisados. A não impregnação dos lipídios produzidos pela queima da biomassa em questão, a madeira, foi averiguada pela não constatação da presença de compostos, ou famílias de compostos, comumente produzidos durante a combustão: compostos aromáticos (tais como fenantreno e pireno), hidrocarbonetos (CPI $\cong 2,6$; "Carbon Preference Index"), álcoois saturados (CPI > 20) e ácidos saturados (CPI > 4,0) com cadeias superiores a 20 átomos de carbono ${ }^{22}$.

Os lipídios com origem anterior à queima (da pasta de argila e do antiplástico), caso existam, estão presentes em baixas quantidades. Como citado, a temperatura de queima esperada na fabricação do material é de, em média, $500{ }^{\circ} \mathrm{C}^{10}$. Segundo Johnson et $a l .{ }^{11}$, a queima na faixa de temperatura entre 200 e $400{ }^{\circ} \mathrm{C}$ é suficiente para eliminar completamente compostos orgânicos oxigenados (todos os lipídios detectados nos fragmentos de cerâmica possuem funções químicas com oxigênio). Portanto, a temperatura utilizada durante a queima dos vasilhames seria capaz de eliminar esses lipídios detectados nos fragmentos de cerâmica descartando, assim, a sua origem da pasta da argila e/ou do antiplástico. Entretanto, como forma de certificar esta possível presença, a simulação de queima $\left(500^{\circ} \mathrm{C}, 1 \mathrm{~h}\right.$ e $\left.30 \mathrm{~min}\right)$ de um sedimento argiloso foi realizada em laboratório em atmosfera oxidante e redutora (Tabela 3 ). Conforme os resultados obtidos a partir dos perfis cromatográficos, pôde-se observar que nenhum lipídio foi detectado no sedimento resultante da queima em atmosfera redutora como oxidante. Os lipídios do sedimento original tinham como compostos majoritários os ácidos graxos saturados $\left(\mathrm{Ac}_{14: 0}-\mathrm{Ac}_{\text {32:0 }}\right.$, dominantes $\left.A c_{16: 0} \mathrm{e} \mathrm{Ac}_{\text {18:0 }}\right)$, seguidos de álcoois $\left(\mathrm{Al}_{14: 0}-\mathrm{Al}_{32: 0}\right.$, dominantes $\mathrm{Al}_{26: 0}$ e $\left.\mathrm{Al}_{28: 0}\right)$ e hidrocarbonetos $\left(\mathrm{H}_{20: 0}-\mathrm{H}_{31: 0} \text {, dominantes } \mathrm{H}_{29: 0} \text { e } \mathrm{H}_{31: 0}\right)^{21}$, somando um total de 168 $\mu \mathrm{g} \mathrm{g}^{-1}$ de sedimento seco (Tabela 3). Após a queima estes não 
Tabela 2. Composição relativa dos extratos totais de lipídios dos fragmentos de cerâmica e sedimento de mesmo contexto

\begin{tabular}{|c|c|c|c|c|c|c|c|}
\hline \multirow{2}{*}{ Compostos } & & \multicolumn{2}{|c|}{$\mathrm{K} 22 / 2$} & \multicolumn{2}{|c|}{$\mathrm{F} 18 / 5$} & \multicolumn{2}{|c|}{$\mathrm{Q} 21 / 3$} \\
\hline & & Fragmento & Sedimento & Fragmento & Sedimento & Fragmento & Sedimento \\
\hline Ácido dodecanóico & $\mathrm{Ac}_{12 \cdot 0}^{\mathrm{b}}$ & - & - & 1,0 & - & - & - \\
\hline Ácido tridecanóico & $\mathrm{Ac}_{13.0}$ & - & 0,8 & - & - & - & - \\
\hline Ácido tetradecanóico & $\mathrm{Ac}_{14: 0}$ & 4,6 & 1,7 & 3,6 & 0,6 & $\operatorname{Traço}^{\mathrm{e}}$ & 0,2 \\
\hline 4,8,12-TMTD & - & 0,2 & - & - & - & - & - \\
\hline Ácidos iso e anteiso pentadecanóico & $\mathrm{Ac}_{15: 0 \mathrm{r}}$ & 0,4 & 1,8 & 0,6 & - & - & 1,4 \\
\hline Ácido pentadecanóico & $\mathrm{Ac}_{15.0}$ & 0,7 & 0,8 & 0,2 & 0,5 & - & 0,5 \\
\hline Ácido hexadecenóico & $\mathrm{Ac}_{16: 1}$ & 3,5 & - & 0,5 & 2,2 & - & - \\
\hline Ácido hexadecanóico & $\mathrm{Ac}_{16: 0}$ & 26,6 & 14,1 & 24,8 & 5,9 & Traço & 1,9 \\
\hline Ácidos iso e anteiso heptadecanóico & $\mathrm{Ac}_{17: 0 \mathrm{r}}$ & 0,7 & 1,3 & 1,2 & 1,0 & - & 0,5 \\
\hline Ácido heptadecanóico & $\mathrm{Ac}_{17 \cdot 0}$ & 1,2 & 0,8 & 1,1 & 0,9 & - & 0,1 \\
\hline Ácido octadecenóico & $\mathrm{Ac}_{18: 1}$ & 3,9 & 4,6 & 2,1 & 4,4 & - & 2,2 \\
\hline Ácido Fitânico & - & 7,0 & - & 10,6 & & Traço & - \\
\hline Ácido octadecanóico & $\mathrm{Ac}_{18: 0}$ & 15,6 & 12,6 & 15,7 & 2.2 & Traço & 3,1 \\
\hline Ácido nonadecanóico & $\mathrm{Ac}_{19: 0}^{10.0}$ & 0,4 & 1,8 & 0,6 & 0,5 & - & 0,3 \\
\hline Ácido eicosenóico & $\mathrm{Ac}_{20: 1}$ & 3,2 & - & 1,0 & - & - & - \\
\hline Ácido eicosanóico & $\mathrm{Ac}_{20: 0}$ & 0,8 & 2,1 & 2,8 & 1,2 & - & 6,4 \\
\hline Ácido heneicosanóico & $\mathrm{Ac}_{21: 0}$ & 0,2 & 0,3 & 0,1 & 0,3 & - & 0,2 \\
\hline Ácido docosenóico & $\mathrm{Ac}_{22: 1}$ & 1,6 & - & 1,3 & - & - & - \\
\hline Ácido docosanóico & $\mathrm{Ac}_{22: 0}$ & 0,5 & 2,3 & 0,4 & 2,3 & - & 13,4 \\
\hline Ácido triacosanóico & $\mathrm{Ac}_{23: 0}$ & 0,2 & 0,6 & 0,2 & 0,6 & - & 0,7 \\
\hline Ácido tetracosenóico & $\mathrm{Ac}_{24: 1}$ & 0,8 & - & 0,4 & - & - & - \\
\hline Ácido tetracosanóico & $\mathrm{Ac}_{24: 0}$ & 0,4 & 2,2 & 0,4 & 2,1 & - & 5,5 \\
\hline Ácido pentacosanóico & $\mathrm{Ac}_{25: 0}^{24.0}$ & 0,1 & 0,6 & 0,1 & 0,5 & - & 0,6 \\
\hline Ácido hexacosanóico & $\mathrm{Ac}_{26: 0}$ & 0,1 & 1,4 & - & 1,5 & - & 3,6 \\
\hline Ácido heptacosanóico & $\mathrm{Ac}_{27: 0}$ & - & 0,2 & - & 0,2 & - & 0,5 \\
\hline Ácido octacosanóico & $\mathrm{Ac}_{28: 0}$ & - & 2,0 & - & 1,5 & - & 7,6 \\
\hline Ácido nonacosanóico & $\mathrm{Ac}_{29.0}^{20.0}$ & - & 0,4 & - & - & - & 0,4 \\
\hline Ácido tricontanóico & $\mathrm{Ac}_{30: 0}$ & - & 1,2 & - & 1,3 & - & 1,1 \\
\hline Ácido heneitricontanóico & $\mathrm{Ac}_{31: 0}$ & - & - & - & 0,6 & - & - \\
\hline Ácido dotricontanóico & $\mathrm{Ac}_{32: 0}$ & - & 0,4 & - & 1,2 & - & 0,7 \\
\hline Álcool chimílico & $\mathrm{GE}_{16: 0}$ & 0,9 & - & 1,4 & - & - & - \\
\hline Álcool batílico & $\mathrm{GE}_{18: 0}$ & 0,4 & - & 0,5 & - & - & - \\
\hline Álcool eicosanol & $\mathrm{Al}_{20: 0}$ & - & 0,7 & - & 0,6 & - & 0,2 \\
\hline Álcool heneicosanol & $\mathrm{Al}_{21: 0}$ & - & 0,3 & - & - & - & - \\
\hline Álcool docasanol & $\mathrm{Al}_{22: 0}$ & - & 3,3 & - & 2,9 & - & 2,4 \\
\hline Álcool tricosanol & $\mathrm{Al}_{23: 0}$ & - & 0,4 & - & 0,4 & - & - \\
\hline Álcool tetracosanol & $\mathrm{Al}_{24: 0}$ & - & 3,5 & - & 3,2 & - & 5,4 \\
\hline Álcool pentacosanol & $\mathrm{Al}_{25: 0}$ & - & 0,4 & - & 0,4 & - & 0,6 \\
\hline Álcool hexacosanol & $\mathrm{Al}_{26: 0}$ & - & 2,0 & - & 2,4 & - & 3,6 \\
\hline Álcool heptacosanol & $\mathrm{Al}_{27.0}$ & - & 0,3 & - & - & - & 0,2 \\
\hline Álcool octacosanol & $\mathrm{Al}_{28: 0}$ & - & 3,0 & - & 3,8 & - & 2,3 \\
\hline Álcool nonacosanol & $\mathrm{Al}_{29: 0}$ & - & 0,3 & - & 0,5 & - & 0,3 \\
\hline Álcool tricontanol & $\mathrm{Al}_{30: 0}$ & - & 2,7 & - & 3,0 & - & 1,3 \\
\hline Álcool heneitricontanol & $\mathrm{Al}_{31: 0}$ & - & 0,2 & - & - & - & - \\
\hline Álcool dotricontanol & $\mathrm{Al}_{32: 0}$ & - & 1,5 & - & 2,1 & - & 0,8 \\
\hline Heptacosano & $\mathrm{H}_{27: 0}$ & - & 1,5 & - & 0,7 & - & - \\
\hline Nonacosano & $\mathrm{H}_{29: 0}$ & - & 0,3 & - & 0,4 & - & - \\
\hline Heneitriacontano & $\mathrm{H}_{31: 0}^{29: 0}$ & - & 0,9 & - & 0,4 & - & - \\
\hline Colesterol & $\mathrm{C}_{27} \mathrm{H}_{46} \mathrm{O}^{\mathrm{c}}$ & - & 1,5 & 0,1 & 1,2 & - & - \\
\hline Hidroxiácidos + ceto-esterol & - & 1,0 & - & 3,5 & - & - & - \\
\hline Concentração total $\left(\mu \mathrm{g} \mathrm{g}^{-1}\right)^{\mathrm{d}}$ & - & 152 & 85 & 3964 & 667 & $<1$ & 423 \\
\hline
\end{tabular}

a Somente utilizados no cálculo compostos com porcentagens superior ou igual a 0,1\% do total. b Simbologia: Ac (ácido), GE (éter de glicerol), Al (álcool) e H (hidrocarboneto); número anterior aos dois pontos refere-se aos átomos de carbono e posterior ao número de insaturações. Os ácidos foram analisados como ésteres metílicos e os álcoois como éteres trimetilsilil. ${ }^{\mathrm{c}}$ Fórmula molecular. ${ }^{\mathrm{d}}$ Calculado com padronização interna, através das áreas dos picos do padrões $\mathrm{C}_{16} \mathrm{D}_{34}$ ou $5 \alpha$-colestano. e Considerado traço, pois a concentração total dos lipídios detectados não ultrapassou $1 \mu \mathrm{g} \mathrm{g}^{-1}$ de cerâmica. 
Fragmentos
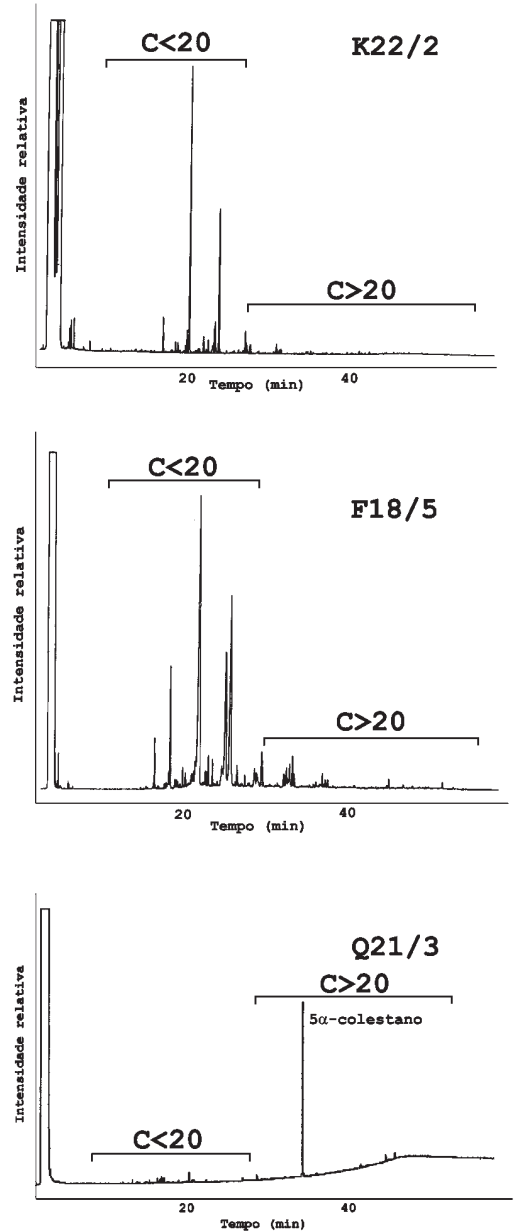

Sedimentos
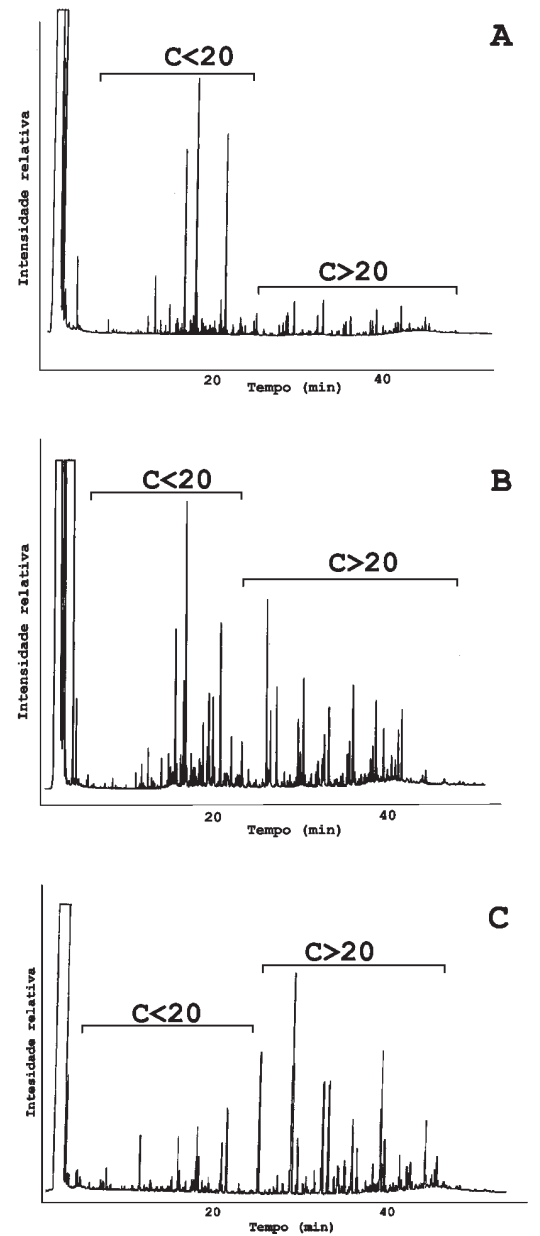

Figura 4. Cromatogramas demonstrando as distribuições dos lipídios presentes nos fragmentos de cerâmica e sedimentos associados, recuperados dos contextos K22/2 (A), F18/5 (B) e Q21/3 (C). Em destaque as regiões características para compostos orgânicos com número inferior e superior a 20 átomos de carbono

Tabela 3. Dados referentes ao teste de simulação de queima à temperatura de $500{ }^{\circ} \mathrm{C}$ por $1 \mathrm{~h}$ e $30 \mathrm{~min}$

\begin{tabular}{|c|c|c|c|}
\hline & $\begin{array}{c}\text { Sedimento } \\
\text { Original }\end{array}$ & $\begin{array}{l}\text { Queimas } \\
\text { Atmosfera } \\
\text { redutora }\end{array}$ & $\begin{array}{c}\text { Atmosfera } \\
\text { oxidante }\end{array}$ \\
\hline Argila (\%) & 44 & - & - \\
\hline $\mathrm{TOC}^{\mathrm{a}}(\%)$ & 4,5 & 2,6 & $\mathrm{nd}^{\mathrm{c}}$ \\
\hline Lipídios $\left(\mu \mathrm{g} \mathrm{g}^{-1}\right)$ & $168 \pm 10^{b}$ & nd & nd \\
\hline
\end{tabular}

${ }^{\mathrm{a}}$ Carbono orgânico total; ${ }^{\mathrm{b}}$ análise em triplicata; ${ }^{\mathrm{c}}$ não detectado.

foram detectados em nenhum extrato orgânico, possivelmente devido à completa volatilização e/ou combustão, comprovando assim o pressuposto acima, no qual a presença de compostos orgânicos da argila original e/ou do antiplástico adicionado à massa de argila não compromete a interpretação de que os lipídios preservados nos fragmentos de cerâmica fornecem dados arqueológicos. Interessante é a presença de carbono orgânico total nas amostras conduzidas no teste com atmosfera redutora. Isto se deve ao fato da ausência de oxigênio favorecer reações de condensação produzindo um material orgânico altamente aromatizado, negro de fumo.

Como dado adicional da não interferência de resíduos que não aqueles de interesse arqueológico (e.g. uso do vasilhame), percebe-se a quase ausência de lipídios no fragmento recuperado do contexto Q21/3 (Figura 4, Tabela 2). A baixa evidência de lipídio nesse fragmento corrobora a conclusão dos testes realizados, ou seja, a ausência de lipídios nesse caso exclui a contaminação por fontes não arqueológicas (por ex., migração do sedimento), mas não vai de encontro às evidencias arqueológicas (uso e/ou tratamento dos vasilhames), uma vez que este vasilhame, do qual teve origem o fragmento, poderia não ter sido usado para armazenar algum produto.

Em trabalhos futuros buscaremos respostas para qual tipo de produto foi processado nos vasilhames: origem vegetal (óleos vegetais, resinas ou folhas) ou animal (gorduras marinhas e/ou terrestre). Para tanto, é prioritária a análise de um maior número de amostras, nas quais um estudo químico precisa ser realizado. Por ex., as diferentes classes e distribuições de compostos químicos precisam ser avaliadas, na tentativa de se criar padrões de classificação que distingam as diversas fontes. Também importante é a análise dos lipídios presentes em amostras de referência contemporâneas (e.g. tecido adiposo de animais terrestres) para posterior comparação com os resíduos preservados. Com isso espera-se recolher, a partir dos resíduos orgânicos preservados em fragmentos cerâmicos, respostas sobre o tipo de material processado no vasilhame original. A partir dessa abordagem, questões arqueológicas como se os grupos eram horticultores e quais os recursos naturais utilizados podem começar a ser elucidadas. 


\section{CONCLUSÕES}

Com base nos dados apresentados é possível concluir que os lipídios detectados nos fragmentos cerâmicos estudados têm como origem o uso e/ou tratamento do vasilhame, concordando com os estudos realizados com fragmentos de cerâmica europeu e norte americano, e que estes sugerem como fonte principal as gorduras de origem animal. Dessa forma, assegura-se que os lipídios preservados em fragmentos de cerâmica arqueológicos guardam informações sobre as atividades do homem do passado, sendo a aplicação deste tipo de análise viável para a obtenção de dados de interesse arqueológico aqui no Brasil.

\section{AGRADECIMENTOS}

Este trabalho só foi possível graças ao auxílio fornecido aos bolsistas F. A. Hansel e S. L. Mireski pelo CNPq. Os autores agradecem aos funcionários da reserva técnica do Museu Universitário Prof. Oswaldo Rodrigues Cabral, C. Castellano e H. Graipel, pela gentileza em ceder as amostras arqueológicas utilizadas nessa pesquisa. Os autores são ainda gratos ao J. R. Estrelau (Central de Análises, DQ - UFSC) pela assistência técnica e aos assessores pelas críticas e sugestões.

\section{REFERÊNCIAS}

1. Evershed, R. P.; World Archaeology 1993, 25, 74.

2. von Stokar, W.; Antiquity 1938, 12, 82.

3. Evershed, R. P.; Dudd, S.; Charters, S.; Mottran, H.; Stott, A. W.; Raven, A.; van Bergen, P. F.; Bland, H.; Philosoph. Trans. Royal Soc. London 1999, B354, 19.

4. Condamin, J.; Formenti, F.; Metais, M. O.; Michel, M.; Blond, P.; Archaeometry 1976, 18, 195; Evershed, R. P.; Arnot, K. I.; Collister, J.; Eglinton, G.; Charters, S.; Analyst 1994, 119, 909; Charters, S.; Evershed, R. P.; Blinkhorn, P. W.; Denham, V.; Archaeometry 1995, 37, 113; Mottram, H. R.; Dudd, S. N.; Lawrence, G. J.; Stott, A.W.; Evershed, R. P.; J. Chromatogr., A 1998, 833, 209; Garnier, N.; Cren-Olivé, C.; Rolando, C.; Regert, M.; Anal. Chem. 2002, 74, 4868.

5. Malainey, M. E.; Przybylski, R.; Sherriff, B. L.; J. Arch. Sci. 1999, 26, 425 .
6. Eerkens, J. W.; Archaeometry 2005, 47, 83.

7. Aillaud, S.; Tese de Doutorado, Universidade de Bristol, Inglaterra, 2001.

8. Dudd, S. N.; Regert, M.; Evershed, R. P.; Org. Geochem. 1998, 29, 1345.

9. Gabasio, M.; Evin, J.; Arnal, G. B.; Middleton, A. P.; Radiocarbon 1986, $28,711$.

10. Heron, C.; Evershed, R. P.; Goad, L. J.; J. Arch. Sci. 1991, 18, 641.

11. Johnson, J. S.; Clark, J.; Miller-Antonio, S.; Robins, D.; Schiffer, M. B.; Skibo, J. M.; J. Arch. Sci. 1988, 15, 414.

12. Miller Jr., T. O.; Arquivos do Museu Paranaense - Nova Série, Curitiba, 1978, vol. 2, 51 .

13. Andrade Lima, T. Em Suma Etnológica Brasileira; Ribeiro, D., ed.; Vozes e FINEP: São Paulo, 1987, vol. 2, 173.

14. Madaceno, A. L.; Monografia, Universidade Federal de Santa Catarina, Brasil, 2001.

15. Alves, M. A.; Clio 1997, 1, 27.

16. Schmitz, P. I.; Instituto Anchietano de Pesquisas, UNISINOS, Documentos 1988, $02,172$.

17. Fossari, T. D.; Tese de Doutorado, Universidade Federal de Santa Catarina, Brasil, 2004.

18. Brochado, J. P.; Calderón, V.; Dias Jr., O. F.; Evans, C.; Maranca, S.; Meggers, B. J.; Miller, E. T.; Nasser, N. A. S.; Perota, C.; Piazza, W.; Rauth, J. W.; Simões, M. F.; Publicações Avulsas, Museu Paraense Emílio Goeldi: Curitiba, 1969, 12, 1 .

19. Bryan, A. L. Em Brazilian Studies; Bryan, A. L.; Gruhn, R., eds.; Oregon: State University, 1993.

20. Piazza, W. F.; Eble, A.; Blumenau em Cadernos, FURB: Blumenau, 1968.

21. Zwirtes, I. R.; Dissertação de Mestrado, Universidade Federal de Santa Catarina, Brasil, 2003.

22. Simoneit, B. R. T.; Appl. Geochem. 2002, 17, 129.

23. Copley, M. S.; Rose, P. J.; Clapham, A.; Edwards, D. N.; Horton, M. C.; Evershed, R. P.; Antiquity 2001, 75, 538.

24. Enser, M. Em Analysis of Oilseeds, Fats and Fatty Foods; Rossell, J. B.; Pritchard, J. L. R., eds.; Elsevier: London, 1994.

25. Gold, A. J.; J. Chem. Soc. 1958, 3, 934.

26. Frankel, E. N.; Neff, W.E.; Rohwesser, W. K; Khambay, B. P. S.; Garwood, R. F.; Weedon, B. C. L.; Lipids 1977, 12, 901.

27. Frankel, E. N.; Lipid Oxidation, The Oily Press, Bell and Bain Ltda: Glasgow, 1988.

28. Annam, M.; LeQuesne, P. W.; Vouros, P.; J. Am. Soc. Mass Spectrom. 1993, 4, 327.

29. van-Bergen, P. F.; Bull, I. D.; Poulton, P. R.; Evershed, R. P.; Org. Geochem. 1997, 26, 117.

30. Hedges, J. I.; Oades, J. M.; Org. Geochem. 1997, 27, 319.

31. Charters, S.; Evershed, R. P.; Goad, L. J.; Leyden, A.; Blinkhorn, P. W.; Denham, V.; Archaeometry 1993, 35, 211. 